\title{
BRILLIANT, SUNNY AND BRIGHT: GENERALISED IINVARIANCE THROUGH ETYMOLOGY
}

Georgios loannou, University of Chile, Faculty of Philosophy and Humanities, Department of Linguistics, georgios@u.uchile.cl

Original scientific paper

DOI: 10.31902/fll.36.2021.12

\begin{abstract}
The relevance of image schemas in metaphoric extension has been long highlighted in Cognitive Linguistics literature. The image-schematic makeup of a metaphoric source is preserved in the target, in a way consistent with the structure of the latter (Lakoff, 1993). More recently, Sullivan (2013) has raised a similar case for semantic frames, in a constructional framework. Metaphoric mappings are licensed only if the semantic frame of the source is compatible with the conceptual metaphor profiled by the target. The present work integrates Sullivan and Lakoff's approach to invariance, on the basis of the following hypothesis: the compatibility between a semantic frame evoked by a lexical construction and a conceptual metaphor is susceptible to an imageschematic blueprint, already present in the etymologically prior meaning of the construction. Thus, invariance is hypothesised to hold across categorisation levels of different schematicity, but also across time. The case study re-takes the analysis of the adjectival terms brilliant, sunny and bright, under the generalised invariance hypothesis. The metaphorical potential of a term is shown to be at the same time constrained as well as motivated by this strong version of invariance.
\end{abstract}

Keywords: image schemas, semantic frames, cognitive topology, structure preservation, etymology. ${ }^{1}$

\section{Introduction}

Semantic extension has been one of the central themes of concern, almost from the inception of Cognitive Linguistics as a distinct research paradigm. In fact, the theory of prototypes (Rosch, 1973; Rosch, 1975; Rosch and Mervis, 1975; Rosch, Mervis, Gray, Johnson and BoyesBraem, 1976) that has greatly informed Cognitive Linguistics, is precisely about this: a realistic treatment of meaning that does justice to the experiential nature of humans' conceptual projections. These are not

\footnotetext{
${ }^{1}$ This paper is embedded in a Fondecyt research project (Fondecyt Regular), ref. num. 1211744, funded by ANID (Agencia Nacional de Investigación y Desarrollo)
} 
given objectively on the basis of states of affairs that exist 'out there' (cf. Kim, 1979; Armstrong, 1997; Reicher, 2009; Geeraerts, 1999; Harder 1999), but are rather the result of categorisation (Taylor, 2003), a mental process rooted in humans' embodied cognition.

Given that categorisation is not given by objectively given conditions that regulate the truth of our statements (cf. Davidson, 1984) but through processes that reflect the flexibility of human apprehension, it follows that categorisation is not fixed once and for all either. Instead, it is based on a prototypical conceptual core with a concomitant range of variation. Categorisation then balances across a tension with two extremes: stability and change. Hence, a question that arises to this connection is how far conceptual variation over a prototype can reach, without losing track of its prototypical ascendance. Additionally, variation has two dimensions: a synchronic and a diachronic one (Geeraerts, 1997). Both are interrelated, as synchronic fluctuations of meaning may result to the entrenchment (Schmid, 2007) of a new extended core, often resulting into a new lexical sense and thus to a new prototype. Nevertheless, the same question naturally arises, concerning non-literal extension: is there a stable prototypical core within a term relevant to its metaphorical potential?

Much work on metaphor has tried to address the question of the compatibility between a metaphoric source and a target, such as LOVE is a JOURNEY (Lakoff, 1990; Lakoff, 1993), understanding the phenomenon as a case of semantic extension. The domain of JOURNEY, as a metaphoric source, extends its meaning so that it encompasses that of LOVE. Conversely, the domain of LOVE selects characteristics of JOURNEY so that it is re-categorised under the conceptualisation of JOURNEY. Lakoff (1990) and much subsequent work argue that metaphorical mappings preserve the cognitive topology of the source domain, in a way consistent with the inherent structure of the target domain (Lakoff, 1993: 215). To take the aforementioned example, the inference in the LOVE domain between a problem encountered within a love relationship and breaking up as a possible outcome, must be consistent with the inferences that hold in the source domain, namely that of JOURNEY. Concretely, the relationship projected as a vehicle may present the travellers with a problem and this may lead to the end of the journey. Lakoff (1993: 215) also argues that preservation of the structure, what he terms Invariance Hypothesis, is operative at a higher level of categorisation. Accordingly, it is not a CAR that is projected as a source targeting a LOVE RELATIONSHIP, but VEHICLE. This could very well be a BOAT, a BUS, etc. Hence, he argues for a cognitive imageschematic topology that gives rise to the preservation of structure 
between the metaphorical source and target. He argues for the relevance of image-schemas such as CONTAINER, PATH and FORCE to the understanding of more abstract and subjective domains such as CATEGORISATION, LINEAR SCALE and CAUSATION. He goes further to say that, possibly, all propositional structure is really image-schematic. In other words, propositional inferences arise from the inherent topological structure of the image-schemas mapped by metaphor onto more abstract concepts such as TIME, STATES, CHANGES, ACTIONS, CAUSES, etc. Essentially, the way to arrive at a general-level schema for some knowledge structure is to extract its image-schematic structure, so that a source and a target are both categorised through this structure, as can be depicted in figure 1 :

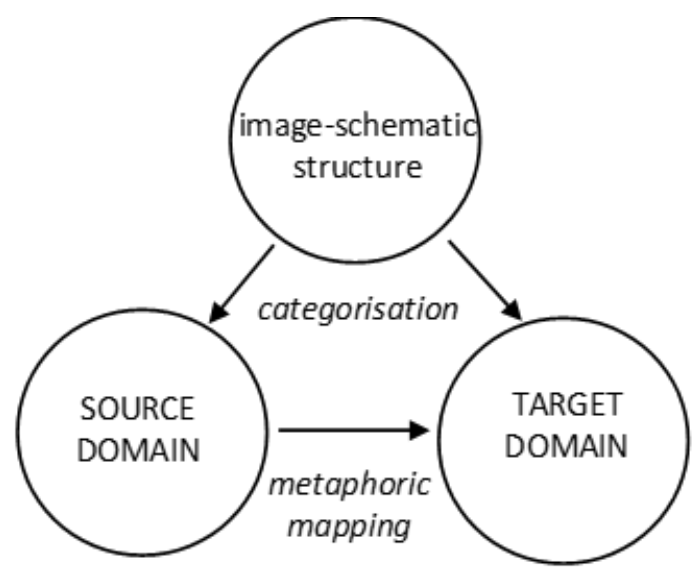

Figure 1. metaphoric mapping as an image-schematic categorisation

More recently, Sullivan (2013) calls on the relevance of semantic frames as a driver for metaphoric mapping. She restates the invariance principle of Lakoff in terms of the conceptual-semantic structure evoked by a given construction (Salivan, 2013: 3.2), the latter understood broadly from being a grammatical schema to comprising a symbolic pair of sound and meaning, namely a lexical item. In her view, the semantic frames' detailed structure residing in a metaphoric source passes over the target. Hence, gestaltist compatibility between source and target is not evaluated only at an image-schematic level, but also at the level of the construal that a semantic frame imposes over a more general domain such as LIGHT, BODY or MIND. The constructions that externalise these domains are taken to structure sub-regions of those domains, such as LIGHT into LIGHT_MOVEMENT or LIGHT_LOCATION. 
The importance of Sullivan's work resides in understanding metaphoric mapping not simply in terms of conceptually entrenched networks of relations among domains in the abstract, but on the basis of the conceptual component evoked by specific entrenched lexicogrammatical units. Nevertheless, although it intends to extend the image-schematic relevance to that of semantic frames evoked by constructions and not substitute for it, in practice there is very limited discussion dedicated to image-schemas. Hence, a relevant question arises regarding the extent to which image schemas and semantic frames are compatible, or in a stronger scenario homomorphic, ${ }^{2}$ when they come to categorise a metaphoric source and a target. In the same connection, a related question arises, regarding the extent to which the image-schematic structure mediating between metaphorical source and target in figure 1 above, is homomorphic to the one underlying the literal prototypical meaning of the lexical construction? Answering the question has consequences for the way we understand the metaphorical potential of the various terms as constructions. These may very well be synonymous or near synonymous, but they may possess an underlying schematic structure that differentiates them in terms of their metaphorical potential. Conversely, constructions that evoke different semantic frames may possess an identical or near identical schematic topology that renders them "metaphorically", so to speak, "synonymous". Concluding that the prototypical literal imageschematic core within a lexical construction constrains its potential for metaphorical extension presents also a diachronic interest, as one of the ways prototypicality has been defined is a term's etymological, or otherwise historically prior, meaning (Evans and Tyler, 2006).

The remainder of the paper has the following structure: sec. 2 reviews Sullivan's work on the semantic-frame differences between brilliant and sunny, as determinant of their distinct behaviour when it comes to metaphoric mappings; sec. 3 recasts the aforementioned contrast on an image-schematic basis, tracing the latter in the etymological origin of the two terms. It is examined if the differential construal imposed on a domain by the semantic frames actually repeats the configuration imposed on the same domain by the prototypical image-schematic topology of the terms. It is also shown how the composite metaphors activated by the semantic frames of the terms may be decomposable into primary metaphors mapped with onto parts of these historically traced prototypical gestalts. A hypothesis on strong

\footnotetext{
${ }^{2}$ structure-preserving map, with possibilities for variable strength of structure preservation.
} 
invariance between image-schemas as prototypes and frames is then postulated for metaphorical extensions; in the light of this hypothesis, sec. 4 examines the term bright's behaviour, which appears less constraining regarding the metaphors it can activate. The results of the analysis are again compared with those in Sullivan (2013) for the same term. Some concluding remarks follow in sec. 5 .

\section{Brilliant vs. sunny and semantic-frame invariance.}

The negligence of constructional facts in the early days of Cognitive Linguistics looked somehow justified, as attention was put on metaphor as a conceptual phenomenon. In Lakoff and Johnson's (1980) words, "metaphor is not just a matter of language- that is mere words". This tendency became generalised and works on semantic extension focused on the conceptual network that human's have entrenched in their minds. This was based on propositional relations rather than grammatical constructions (Crisp, 2002; Crisp, Heywood and Steen, 2002). Nevertheless, in the light of work that realised the relevance of constructions both in conceptual and cognitive terms (Goldberg, 1995; Goldberg, 2006), Sullivan's work (2013) is motivated by the need to understand metaphor realistically, as a usage-based phenomenon. In this sense, metaphors are motivated not only by the conceptual link between pre-existing propositions "in the abstract", but as constructions that evoke frames that are "configured" for specific conceptually relevant details. Under the perspective of treating conceptual and formal structure as harmonious to each other (Goldberg, 2003), an integrated theory that encompasses both constructions and propositional structures is only natural.

In this light, Sullivan (2013: chpt.3) looks into the effect the semantic frames evoked by lexical items have onto the metaphorisation of domains. Her foundational observation is that domains do not have a uniform behaviour when they participate in metaphorical mappings. In contrast, the detailed structure within frames is determinant of the specific type of conceptual metaphor that will be activated.

One of the cases analysed in her work are the near-synonymous adjectives such brilliant and sunny (Sallivan, 2013: chpt. 3). Both of them sanction the same semantic domain, namely LIGHT. Nevertheless, their metaphorising potential depends on the semantic frames that are linked to each word and configure further the domain of LIGHT in more semantic detail. Concretely, brilliant activates the LIGHT_MOVEMENT frame, whereas sunny the LOCATION_OF_LIGHT frame. Consequently, for a mapping that sanctions the conceptual metaphor INTELLIGENCE IS LIGHT EMISSION, it is only the adjective brilliant that can be used. 
Conversely, and in accord with invariance hypothesis, the metaphoric target selects brilliant's structure only if its own semantic frame contains elements that justify the use of the construal that the metaphorical source imposes on the domain of LIGHT. Such an element would be SCIENTIST, STUDENT, etc., which activates -among others- the semantic frame of intelligence. This is the reason that (1) is acceptable whereas (2) is not:

(1) This student's work is always brilliant.

(2) ?The student handed in a sunny work.

Brilliant, on the other hand, cannot be used to metaphorise a state of happiness, as in (3), because the frame needed here is one that construes light as a property of a static landmark, as in (4):

(3) ? His disposition has always been brilliant.

(4) The room is really sunny.

In contrast, sunny is easily interpreted with the meaning of HAPPYDELIGHTFUL, given that emotions are metaphorically understood as STATES:

(5) He always looks on the sunny side of things.

Integrating the literal conceptual charge of semantic frames into conceptual metaphor theory is definitely a step forward towards a motivated constructional semantics. Additionally, linking semantic frames to specific lexico-grammatical constructions as the result of entrenched usage-based events (Langacker, 2008) opens the door to a realistic semantics that encompasses synchronic and diachronic variation. Nevertheless, as said above, there is a link missing that regards a systematic way of relating image schemas with semantic frames under the hypothesis of invariance. This is what the next section turns to, retaking the analysis of the contrast between brilliant and sunny.

\section{Brilliant vs. sunny and their image-schematic constitution.}

\subsection{Brilliant}

Let us first turn to the issue of the compatibility of the semantic frame evoked by a term with the image-schematic constitution of it traced through its etymological origin, contrasting in this respect brilliant and sunny.

Oxford English Dictionary informs us that brilliant is first attested in $17^{\text {th }}$ century with the meaning of SPARKLING WITH LIGHT, used both as an adjective but also as a noun, specifying a type of diamond (ex: 6-7). The term is a descendant of French brillant SHINING, present participle of briller, roughly meaning SHINE, ultimately being traced into Latin 
beryllus (ex. 8), which means BERYL, a precious stone physically found in crystallic form:

(6) Lost... a square Diamond Brilliant, weighing eight grains (London Gaz. 1690)

(7) Brilliant: glittering, sparkling, shining (Blount's Glossographia, ed. 5. 1681)

(8) ponesque in eo quattuor ordines lapidum...in quarto chrysolitus onychinus et beryllus.

'You shall set in it four rows of stones...ruby, topaz, and beryl shall be in the fourth row' (Vulg. Exod. 28. $4^{\text {th }} \mathrm{C}$. CE)

One of the archetypical characteristics of crystals is their ability to refract light and reflect it in the form of a beam, as if the crystal itself were the light source and the light a property emanating from the crystallic surface itself. This characteristic of crystals generates a schematic "topology", in Lakoff's sense of the use of the term, where light is directionally moving through a narrow direct PATH towards a landmark, in most of the cases a human perceiver of the ray. The image schema associated with the process is shown in figure 2 , where the crystal is the trajector TR, the human perceiver the landmark LM and the ray the property emanating from TR towards $L M$ :

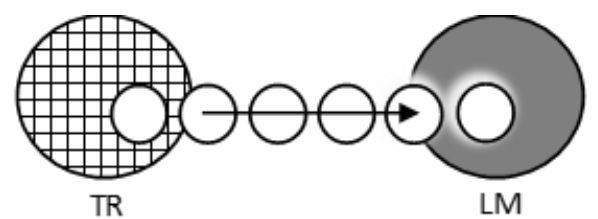

Figure 2. image schema of beryl's conceptualisation

This schema not only is well rooted in experiential/embodied realism advocated by Cognitive Linguistics (Johnson and Lakoff, 2002), but also contains all components that can give rise to the more detailed structure of the semantic frame of brilliant, as we will see immediately below.

We saw that Sullivan (2013) argues for a schematic compatibility between the brilliant's frame LIGHT_MOVEMENT and the conceptual metaphor INTELLIGENCE IS LIGHT EMISSION, which licenses the use of brilliant for expressing intelligence. Nevertheless, INTELLIGENCE IS LIGHT EMISSION - that itself improves on Master List's metaphor INTELLIGENCE IS A LIGHT SOURCE (Lakoff, 1991)- is not sufficient to motivate the metaphorical use for two reasons: first, emission of light describes an ontology that seems to be too coarse-grained a 
conceptualisation. For example, SUNLIGHT is itself a case of LIGHT EMISSION but in general it is not used to depict intelligence:

(9) ? Her mind is the light of the sun.

Although it can be argued that the awkwardness of (9) is due to lack of entrenchment of the specific expression in a metaphoric mapping, this does not prevent it from being used in a non-entrenched HAPPINESS-related metaphor:

(10) Her disposition is the light of the sun.

On the other hand, non-entrenched expressions such as the light of a thunder sounds much better than (9), when used in the context of intelligence:

(11) Her mind is the light of a thunder. ${ }^{3}$

Finally, if the expression light of sun is replaced by ray of sun, ${ }^{4}$ INTELLIGENCE is again more compatible as a metaphoric target than in (9) within the LIGHT_EMISSION metaphor:

(12) Her mind is a ray of sun.

We thus observe that it is not all instances of LIGHT EMISSION that can sanction the metaphoric interpretation of INTELLIGENCE. It seems that, although more detailed than the general domain LIGHT, semantic frames need a further elaboration that distinguishes between acceptable instances of a semantic frame, on the one hand, and nonacceptable ones, on the other. Nevertheless, this elaboration cannot follow the way of more encyclopaedic details, in the sense of distinguishing, say, between BEAM, RAY, THUNDERLIGHT, LAMPLIGHT, etc. In contrast, the details must be given from configurations at an intermediate level between domains and frames, and they must function as a topological blueprint onto which semantic frames can fit or not. I argue that these configurations are precisely image schemas.

The gestalt in figure 2 as a schematisation of the etymologically traced referent of brilliant, namely a crystal-like material, comprises all components of a topology that gives rise to a specific type of LIGHT EMISSION: a trajector understood as a LIGHT SOURCE, LIGHT perceived

\footnotetext{
${ }^{3}$ Given that the examples are intentionally non entrenched, the judgments on (9)-(12) are based on 12 native speakers that unanimously have confirmed the intuitions behind those examples.

${ }^{4}$ Independently also sanctioning the HOPE is LIGHT metaphor (Lakoff, 1991: 152).
} 
as a property of the trajector, a directional trajectory of narrow PATH that the light follows, and an ANIMATE PERCEIVER, whose subjective awareness receives the light.

To what extent is this image schema compatible/homomorphic to the conceptual metaphor INTELLIGENCE IS LIGHT EMISSION? Sullivan assumes a corresponding function from the conceptualisation constructionally associated to the adjective, to the conceptual metaphor. Nevertheless, in accord with Murhy's (1996) reservations about the claim that that a metaphorical target at the same time possesses an inherent delimiting framing as well as a more abstract structure, it seems plausible that the underlying image-schematic gestalt in figure 2 already contains the components making up the metaphorical source. More concretely, INTELLIGENCE as LIGHT EMISSION can be decomposed into more primary metaphors (Grady, 1997; Lakoff, 1998) along the following lines: MIND as a LOCATION to which KNOWLEDGE as OBJECT is transferable is instantiated by the LM. The EXISTENCE of KNOWLEDGE as LOCATION HERE is manifested as VISIBILITY within the egocentric subjectivity of the MIND. KNOWLEDGE as VISIBILITY is instantiated by the actual emanation of LIGHT from the beryl-source. Once transferred, it is this VISIBILITY-AWARENESS that becomes part of the LM. Coming from a source, KNOWLEDGE as LIGHT is conceptualised as an OBJECT proper to its source. The source is mapped on the POSSESSOR of the OBJECT, instantiated by the human being-TR:

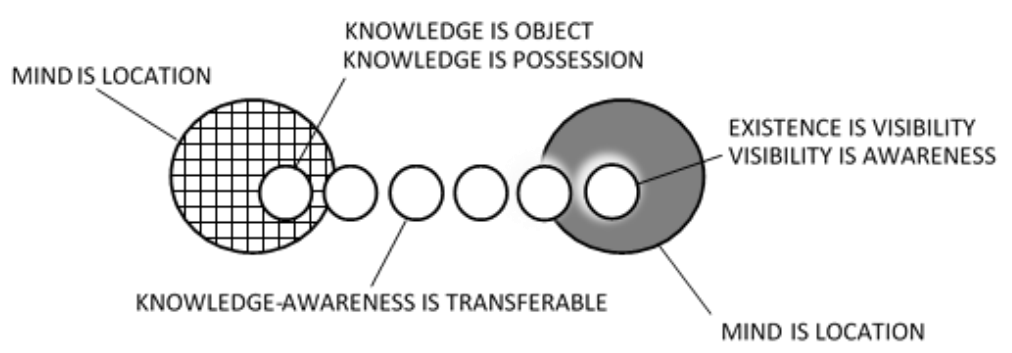

Figure 3. image-schematic decomposition of INTELLIGENCE

What we see is that, essentially, figure 3 is an image-schematic configuration of INTELLIGENCE, without the latter being defined as such. We have a gestaltist schematisation of a semantic frame at an imagistic level $^{5}$, much more detailed than LIGHT EMISSION, but much more

\footnotetext{
${ }^{5}$ Imagistic with the very broad interpretation of the term, not necessarily visually perceived nor static (cf. Hampe 2005)
} 
schematic than the latter's metaphoric target. More importantly, LIGHT EMISSION as a source for metaphorising INTELLIGENCE is included in the gestaltist decomposition of the latter, possibly as a focal part of it. In a relevant sense, brilliant's image schema, its metaphoric potential and INTELLIGENCE's semantic frame are the same entity, at different levels of schematisation and detail.

\subsection{Sunny}

As said above, sunny is interpreted as configuring the domain of LIGHT as LIGHT_LOCATION. Given that there is an independently motivated conceptual metaphor EMOTIONS ARE LOCATIONS, sunny is used as a source to express the emotion of HAPPINESS. Nevertheless, as was too the case for brilliant, in Sullivan (2013) it is not explained how the link between the semantic frame LOCATION_OF_LIGHT and sunny is motivated. The explanation as being simply constructionally linked does not escape the problems of arbitrariness of the relation between signifier and signified within the Saussurian symbolic sign (Saussure, 1916; Manfu, 2012). Motivation of the relation between form and function has been a central theme within Cognitive Linguistics and Cognitive Science at large (Kreitler, 2013), and any move towards this direction is beneficial. Constructions as a kind of form are also motivated by the concepts to which they are associated, a phenomenon of "harmonisation" between schematic constructional features and semantic structure (Goldberg, 1995; Goldberg, 2003).

Let us then first look at the rather more obvious etymological origin of sunny, which will help us construct the image schema associated with the adjective. OED informs that sunny, first time attested in $14^{\text {th }} \mathrm{C}$. CE, is an adjective that originally refers to DAYTIME, namely to the temporal span where there is sunlight:

(13) Was there neuer sonnye day so cleere

'There has never been so clear a daytime' (F. J. Furnivall Polit., Relig., \& Love Poems, c1500 CE).

It is always within noun phrases with heads such as day, morning, time, etc., that this meaning of sunny is found. Slightly later the term's meaning extends to that of BRIGHT, modifying nouns such as climate, place, weather, etc.:

(14) He'le turne his glory from the sunny clymes...

'He will turn his glory from the sunny places...'

(T. Campion Obseruations Art Eng. Poesie iv. sig. B3, 1602 CE). 
Quite early, the figurative meaning of PLEASANT, CHEERFUL, HAPPY, is also attested:

(15) I left your sonnye sight with teares

'I leaft your sunny face with tears'

(B. Garter Tragicall Hist. Two Eng. Louers f. 48ㄴ, 1565 CE).

We see that, in contrast to brilliant, sunny profiles an adjectival trajector coaligned to the temporal span during which sun is visible, in some sense contrasting to the "dark" span of the daily period:

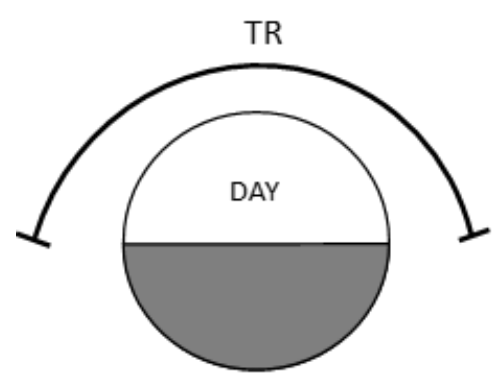

Figure 4. image schema conceptualisation of sunny

The distinction between EMISSION and SPAN is the key-difference between the two construals motivated by the terms, brilliant and sunny, respectively. It is only the latter that can be conceived holistically (see Langacker, 2008: chpt. 4 on the notion) and bounded within welldefined limits.

Someone would argue that sunny makes a more direct reference to time, given that it is linked to a temporal span, and for this reason should sanction a processual and not a static and "reified" entity. Nevertheless, Cognitive Grammar draws a careful distinction between ontological categories and a categorisation of a higher-level schematicity (Langacker, 2008: chpt. 4). This schematicity lies beyond detailed semanticity and can motivate conceptualisations that apparently contradict their ontology. Hence, although sunny may originally be related to duration, the latter is understood rather statically. I argue that this is the reason that has helped extend the adjectival trajector to a spatial one, a meaning that sunny has retained from then onwards.

Thus, interpreting LIGHT as LOCATION as the semantic frame evoked by the term sunny, is image-schematically motivated and not arbitrarily linked within the lexical construction of sunny. Subsequently, the metaphorisation of HAPPINESS as LIGHT passes through the 
metaphorisation of EMOTIONS as LOCATIONS (Lakoff, Espenson and Schwartz, 1991). Again, the metaphor is embedded within the imageschematic makeup of the scene and not independently motivated. Semantic frames, image-schemas and metaphoric potential seem to be homomorphic to each other, as they all share the same schematic structure.

\section{Bright}

Sullivan's discussion on the contrast between sunny and brilliant is complemented by the analysis of the adjective bright. Nevertheless, as Sullivan notes (Sullivan, 2013: 44), this adjective is compatible with both metaphorical interpretations. Bright can be used either to map INTELLIGENCE and LIGHT-EMISSION or HAPPINESS and LIGHT, as shown below:

(16) She wrote a bright article.

(17) Grandma is always in a bright mood.

Sullivan concludes that the adjective in its literal sense evokes both semantic frames, namely LOCATION_OF_LIGHT frame, as in bright room, and the LIGHT_MOVEMENT frame, as in bright fire or bright moon (op. cit.). She adds that in accordance with Invariance Principle, this ability for dual frame evocation is preserved in its metaphoric uses. Bright in the expression bright room has its metaphorical correspondence in examples such as bright mood, whereas bright in an expression such as bright fire corresponds to a metaphorically extended use such as in bright article. Hence, as a result, bright can exceptionally metaphorise both HAPPINESS and INTELLIGENCE. Nevertheless, Sullivan notes in passing that, although both bright and brilliant can express INTELLIGENCE as LIGHT EMISSION, there is an asymmetry between the two: bright expresses INTELLIGENCE to a lesser degree than brilliant. This is shown through the selectional preferences of the adjectives. Bright most often refers to CHILDREN or STUDENTS. Thus, we can say bright child, bright boy, or bright pupil. On the other hand, brilliant tends to select arguments such as brilliant engineer, scholar or scientist. ${ }^{6}$ The somehow tentative explanation that Sullivan gives is that "the values assigned to the degree element in the LIGHT_MOVEMENT frame" for each adjective are transferable onto the target domain. Sullivan argues that because brilliant involves a greater degree of LIGHT_EMISSION than bright, the two adjectives denote differing degrees of INTELLIGENCE.

In the light of the search for conceptual motivation in the link between lexical constructions and the semantic frames that they evoke,

\footnotetext{
${ }^{6}$ The examples are based on Sullivan's own corpus analysis.
} 
the argumentation on the dual construing ability of bright may seem rather ad hoc, having a status of exception. Similarly, the argumentation on the lesser ability of bright to metaphorically denote INTELLIGENCE in comparison to brilliant, is somehow circular. Hence, the question that arises is the following: what is the factor that renders bright less constrained in its construing ability? More specifically, and in line with the strong version of invariance hypothesis put forward in the present work, can the image-schematic structure of bright lead to this dual metaphorical option? To what extend is this image schema compatible with both frames evoked by the adjective?

Let us then have a look at the etymology of bright and its historically prior meaning. OED gives SHINING and GIVING OFF LIGHT as the meaning first attested in English. The term presents a great number of cognates in various languages, all having similar meanings, ultimately stemming from the Indo-European root underlying Sanskrit bhrāj-, again meaning SHINE.

At a first glance, SHINE is also about LIGHT EMISSION. Nevertheless, there are two etymological facts that assign a particular status to the term. The first concerns its collocational properties. Not only in historical terms, but also in terms of persistence (cf. Evans \& Tyler 2004), the prototypical sense of bright profiles as its trajector CELECTIAL OBJECTS:

(18) Se syxta [planet] is gehaten mercurrus, micel \& beorht.

'The sixth planet is called Mercury, great and bright'

(AElfric, Interrogationes Sigewulfi in Genesin, $10^{\text {th }} \mathrm{C} . \mathrm{CE}$ )

(19)He sette a steorne upp...full brad, and brihht, and shene.

'He set a star up (in the sky)...great and bright and fair'

(Ormulum [Burchfield transcript] I. 3431, c1175 CE)

(20) The altitude of the Mone, or of brihte sterres.

'The hights of the Moon, or the bright stars' (G. Chaucer Treat. Astrolabe, $1391 \mathrm{CE}$ )

(21) That I should loue a bright particuler starre.

'that I should love a bright special star'

(W. Shakespeare All's Well that ends Well, 1623 CE)

(22)That bright Star is Jupiter (Philos. Trans. 1728 CE)

(23)The newly discovered galaxy called Leo $T$ is...50,000 times brighter than the sun (Sci. News 27, 2007). 
Of course, this meaning can also be extended to objects such as fire, eyes, etc., as happens up to today:

(24) A michel fier he sag, and an brigt

'A great and bright fire he saw' (Gen. \& Exod. I. 951, c1325 CE).

(25) Lizzie had a bright face, laughing eyes (Judith Saxon, Nobody's children, $1991 \mathrm{CE}$ )

The second characteristic concerns a very early link of bright with WHITE, today found in a cognate form from Albanian, namely bardhë. In accord with Mallory \& Adams (2006: 329) the proto-Indo-European root may also underlie an early word for the BIRCH, because of the latter's shiny white bark.

Both facts, namely the tendency for the adjectival trajector to be CELESTIAL OBJECTS and the etymological link with a colour property, argue for an image-schematic construal that profiles the adjective as a static property inherent to the adjectival trajector itself and not as a dynamic process emanating from it. In the cases of both brilliant and bright LIGHT SHINING is the ontological -so to speak- base, in other words the initial selection of conceptual content, where emanation of light could be taken as an inferential "truth" holding for both adjectives. Nevertheless, the linguistic presentation of the latter has a very different "windowing of attention" (Talmy, 2000) encoded in the construction of each. Accordingly, windowing in the case of bright narrows itself within the scope of the shining object, as in figure 5 :

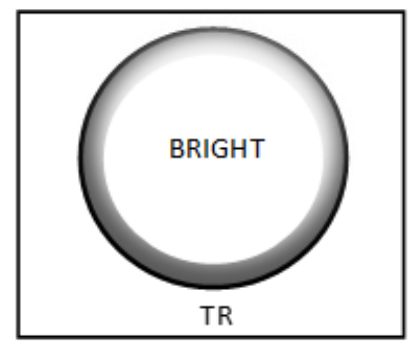

Figure 5. image-schematic conceptualisation of bright.

1 argue that it is precisely this image-schematic constitution in figure 5 that gives rise to the dual metaphorical potential of bright but also causes its lesser ability to metaphorise INTELLIGENCE. We saw that, in the case of brilliant, the concept of INTELLIGENCE is motivated through a schematic but detailed gestalt that includes many primary components: a source-locus of knowledge, the latter's transferability 
through a narrow and direct path towards a landmark, and the metaphorisation of awareness on the part of the landmark through the visibility caused by the emission of light on the part of the trajector. In the case of bright, though, no knowledge becomes part of the landmark's awareness, entering its locus. KNOWLEDGE as LIGHT exists and is sanctioned on independent grounds of conceptual metaphor but it stays confined within the scope of the trajector, as a property inherent to it. No subjective awareness of this KNOWLEDGE as LIGHT is involved. Hence, we see that the aforementioned "lesser degree of light emission" is rooted in the image-schematic makeup of the term. We also infer that, on the basis of Sullivan's observations (Sullivan 2013: 44), the semantic type of the adjectival trajector has a very restricted range of possible instantiations. As an example, look at the following contrast:

(26) He is a brilliant speaker.

(27)That was a brilliant speech.

(28)He is a bright speaker

(29)?That was a bright speech.

(30)He is a brilliant scientist

(31)That was a brilliant article

(32)He is a bright scientist

(33)?That was a bright article.

Although somehow tentative and in need for further corpus-based support, the conclusion is that THINGS such as ARTICLE and SPEECH that infer more directly the product of KNOWLEDGE and its effect on the subjectivity of the recipient of KNOWLEDGE are banned. ${ }^{7}$ This tells us again something on the possibility of decomposition of composite metaphors through their primary image-schematic components.

Finally, the interpretation of bright as HAPPY/CHEERFUL uses the simple topology of BRIGHTNESS as a PROPERTY confined within an entity, so that it extends LIGHT into HAPPINESS. The link is independently well rooted in our experiential life, where our positive emotions are metonymically linked to the beneficial presence of LIGHT,

\footnotetext{
${ }^{7}$ Bright article seems to be better than bright speech. Nevertheless, the difference may again be due to the same principle: an article can function as a source of knowledge independently of its author, having an autonomous "existence". Further research is needed that can confirm or not the intuition, based on the analysis of a more extensive corpus.
} 
giving rise to the metaphoric generalisation LIGHT is HAPPINESS (Kövesces, 1991; Kövesces, 2013).

\section{Conclusions}

The present work put into test a strong version of invariance for metaphoric mappings. It looked into the possibility of unifying Lakoff's structure preservation on the one hand, and Sullivan's version of the same hypothesis for semantic frames evoked by lexical constructions, on the other. Furthermore, it did so along both a synchronic and a diachronic dimension. Synchronically, the analysis tested the hypothesis that the way the semantic frames configure domains such as LIGHT into more specific construals such as LIGHT_MOVEMENT or LIGHT_LOCATION, is not arbitrarily linked to the lexical construction but homomorphic to the latter's image-schematic makeup. Thus, metaphors such as INTELLIGENCE IS LIGHT EMISSION would have their image-schematic blueprint immanent in a construction such as brilliant. Diachronically, the analysis hypothesised that this immanence stems from the historically prior meaning of the lexical construction, traceable etymologically. In this way, invariance gains in motivation and is shown to be a constant constraining factor for metaphoric extension of a given term. The terms examined, namely brilliant, sunny and bright, to a great extent favour the hypothesis of strong invariance. It is shown that each of the terms is image-schematically distinct and that their distinct image-schematic origin is repeated through the semantic frame evoked by their lexical construction. Even more interestingly, the metaphors activated by each of the term are in a relevant sense already embedded in the construction of those, decomposable into primary metaphors that correspond to parts of the terms' image-schematic gestalt.

Thus, brilliant is shown to present the most complex image schema, stemming from the original meaning of the word, BERYL. The LIGHTSOURCE trajector, the LIGHT as a transferable property along a narrow and direct PATH and the locus where LIGHT rests on the landmark, map nicely on all primary metaphors underlying the conceptual metaphor INTELLIGENCE IS LIGHT EMISSION, where knowledge as visibility enters the subjective awareness of the knowledge's receiver.

Sunny, on the other hand, profiles a reified and static spatial coalignment to that of a bounded temporal period. Thus, the distinction between EMISSION and SPAN appears to be the critical difference between the two construals motivated by the terms brilliant and sunny, respectively. The holistic construal of the second maps sunny naturally on emotional states such as HAPPINESS, long found in literature to be conceptualised as bounded areas. 
Finally, the dual possibility of interpreting metaphorically bright either as HAPPY or INTELLIGENT, follows from its simpler image-schema, where LIGHT is construed as a property inherent to the adjectival trajector. This gestaltist simplicity can assume both KNOWLEDGE and HAPPINESS as its elaboration, but it interprets it without linking it to the subjective awareness that observes it.

The importance of this short study consists in a realistic and empirically traceable connection between image-schemas, semantic frames and conceptual metaphor theory. Metaphoric mappings as categorisations may be actually much more embedded in the literal meaning of constructions, immanent to both image schemas and semantic frames. Finally, if metaphoric meanings have a diachronic blueprint preserved for periods of hundreds or even thousands of years, then the invariance hypothesis is possibly at work for literal extension too, constraining the range of possible semantic changes a term undergoes. I leave this matter for future research, along with a corpusbased enrichment of the present work.

\section{Works Cited:}

Armstrong, David M. A World of States of Affairs. Cambridge, UK: Cambridge University Press, 1997.

Crisp, Peter. 2002. "Metaphorical Propositions: A Rationale." Language and Literature 11 (2002): 7-16. Print.

Crisp, Peter, John Heywood and Gerard Steen. 2002. "Metaphor Identification and Analysis, Classification and Quantification." Language and Literature 11 (2002): 55-69. Print.

Davidson, Donald H. Inquiries into Truth and Interpretation. Oxford, UK: Clarendon Press, 1984.

Duan, Manfu. "On the arbitrary nature of linguistic sign." Theory and Practice in Language Studies 2.1 (2012): 54-59. Print.

Evans, Vyvyan, and Andrea Tyler. The Semantics of English Prepositions. Special Scenes, Embodied Meaning and Cognition. Cambridge, UK: Cambridge University Press, 2004.

Geeraerts, Dirk. Diachronic Prototype Semantics. Oxford, UK: Oxford University Press, 1997.

Geeraerts, Dirk. "Idealist and Empiricist Tendencies in Cognitive Semantics." Cognitive Linguistics: Foundations, Scope, and Methodology. Ed. René Dirven, Ronald W. Langacker and John R. Taylor. Berlin/New York: Mouton de Gruyter, 1999. 163-194. Print.

Goldberg, Adele. Constructions: A Construction Grammar Approach to Argument Structure. Chicago/London: Chicago University Press, 1995.

Goldberg, Adele. "Constructions: A New Theoretical Approach to Language." TRENDS in Cognitive Sciences 7.5 (2003): 219-224. 
Goldberg, Adele. Constructions at Work. The Nature of Generalisation in Language. Oxford, UK: Oxford University Press, 2006.

Grady, Joseph. Foundations of Meaning: Primary Metaphors and Primary Scenes. Doctoral thesis, Linguistics Dept, University of California, Berkeley. 1997 (available from UMI Dissertation Services at: www.il.proquest.com/ umi/dissertations/).

Hampe, Beate (ed.). From Perception to Meaning. Image Schemas in Cognitive Linguistics. Berlin: Mouton de Gruyter, 2005. Print.

Harder, Peter. "Partial Autonomy. Ontology and methodology in Cognitive Linguistics." Cognitive Linguistics: Foundations, Scope, and Methodology. Ed. René Dirven, Ronald W. Langacker and John R. Taylor. Berlin/New York: Mouton de Gryuter. 1999. 195-222. Print.

Johnson, Mark and George Lakoff. "Why Cognitive Linguistics Requires Embodied Realism." Cognitive Linguistics 13.3 (2002): 245-263.

Kim, Jaegwon. "States of Affairs, Events, and Propositions." Essays on the philosophy of Roderick M. Chisholm." Grazer Philosophische Studien. Ed. Ernest Sosa. Vols 7-8. 1979. 147-162.

Kövecses, Zoltán. "Happiness: A definitional effort." Metaphor and Symbolic Activity 6.1 (1991): 29-46. Print.

Kövecses, Zoltán. "The Metaphor-Metonymy Relationship: Correlation Metaphors Are Based on Metonymy." Metaphor and Symbol 28.2 (2013): 75-88. Print.

Kreitler, Shulamith (ed.). Cognition and Motivation. Forging an Interdisciplinary Perspective. Cambridge, UK: Cambridge University Press, 2013. Print.

Lakoff, George. "The Invariance Hypothesis: Is Abstract Reason Based on ImageSchemas?" Cognitive Linguistics 1.1 (1990): 39-74. Print.

Lakoff, George. "The Contemporary Theory of Metaphor." Metaphor and Thought. $2^{\text {nd }}$ ed. Ed. Andrew Ortony. Cambridge, UK: Cambridge University Press. 1993. 202-251. Print.

Lakoff, George. Philosophy in the Flesh. The Embodied Mind and its Challenge to Western Thought. New York: Basic Books, 1998. Print.

Lakoff, George et al.1991. Master metaphor list. Berkeley: University of California (available at: http://araw.mede.uic.edu/ alansz/metaphor/METAPHORLIST.pdf).

Lakoff, George, and Mark Johnson. Metaphors We Live By. Chicago: University of Chicago Press, 1980. Print.

Langacker, Ronald. Cognitive Grammar. A Basic Introduction. Oxford, UK: Oxford University Press, 2008. Print.

Mallory, James P., and Douglas Adams. The Oxford Introduction to Proto-IndoEuropean and the Proto-Indo-European World. Oxford, UK: Oxford University Press, 2006. Print.

Murphy, Gregory. "On Metaphoric Representation." Cognition 60 (1996): 173204. Print.

Reicher, Maria Elisabeth (ed.). States of Affairs. Frankfurt A.M.: Ontos Verlag, 2009. Print.

Rosch, Eleanor. "Natural categories." Cognitive Psychology 4 (1973): 328-350. 
Rosch, Eleanor. "Cognitive Reference Points." Cognitive Psychology 7.4 (1975): 532-47. Print.

Rosch, Eleanor and Carolyn Mervis. "Family Resemblances: Studies in the Internal Structure of Categories." Cognitive Psychology 7 (1975): 573-605. Print.

Rosch, Eleanor, et. al. "Basic Objects in Natural Categories." Cognitive Psychology 8 (1976): 382-439.

Saussure, Ferdinand de. Cours de linguistique Générale (ed. by Charles Bally \& Albert Sechehaye, with the assistance of Albert Riedlinger). Lausanne/Paris: Payot, 1916. Print.

Schmid, Hans-Jörg. "Entrenchment, Salience and Basic Level. " The Oxford handbook of Cognitive Linguistics. Ed. Dirk Geeraerts and Hubert Cuyckens. Oxford, UK: Oxford University Press, 2007. 117-138. Print.

Sullivan, Karen. Frames and Constructions in Metaphoric Language. Amsterdam/Philadelphia: John Benjamins Publishing Company, 2013. Print

Talmy Leonard. Towards a Cognitive Semantics, Vol. 1. Cambridge, Massachusetts: The MIT Press, 2000. Print.

Taylor, John. Linguistic Categorization. $3^{\text {rd }}$ ed. Oxford, UK: Oxford University Press, 2003. Print.

\section{BRILLIANT, SUNNY Y BRIGHT: INVARIANCIA GENERALIZADA A TRAVÉS DE LA ETIMOLOGÍA}

Resumen: La relevancia de los esquemas de imágenes en la extensión metafórica ha sido destacada durante mucho tiempo en la literatura sobre lingüística cognitiva. La composición esquemática de la imagen de una fuente metafórica se conserva en la meta, de una manera consistente con la estructura de esta última (Lakoff 1993). Más recientemente, Sullivan (2013) ha planteado un caso similar para los marcos semánticos, en un marco de construcción. Las asignaciones metafóricas son permisibles solo si el marco semántico de la fuente es compatible con la metáfora conceptual perfilada por la meta metafórica. El presente trabajo integra este enfoque sobre invariancia de Sullivan y Lakoff, a partir de la siguiente hipótesis: la compatibilidad entre un marco semántico evocado por una construcción léxica y una metáfora conceptual es susceptible de un plano imagen-esquemático, ya presente en el significado etimológicamente primario de la construcción. Por lo tanto, se plantea la hipótesis de que la invariancia se mantiene en los niveles de categorización de diferente esquematización, pero también a lo largo del tiempo. El estudio de caso retoma el análisis de los términos adjetivales brillante, soleado y brillante, bajo la hipótesis de invariancia generalizada. Se muestra que el potencial metafórico de un término está al mismo tiempo limitado y motivado por esta fuerte versión de invariancia.

Palabras clave: esquemas de imagen, marcos semánticos, topología cognitiva, preservación de estructuras, etimología. 